\title{
LA LITERATURA INFANTIL EN LATINOAMÉRICA
}

ANTES y DESPUÉS DE MonTEIRo Lobato

\begin{tabular}{c}
\hline Lúcia Velloso da Silveira ${ }^{*}$ \\
Universidad Federal de Rio de Janeiro \\
\hline
\end{tabular}

Fecha de recepción: septiembre de 2012 Fecha de aceptación: octubre de 2012

RESUMEN: En este trabajo se presentará un recorrido histórico de la literatura infantil brasileña y se resaltará la importancia del autor Monteiro Lobato, quien abrió las puertas para un nuevo tipo de creatividad en la literatura latinoamericana. Su obra es un gran proyecto que le muestra a la infancia no solo el valor esencial de la literatura sino, también, el mundo extraordinario de la cultura. Él supo conjugar los dos factores: la «realidad» en la lectura de la vida junto con la «fantasía» que promueve la «creatividad». A los escritores que vendrían después, tanto brasileños como latinoamericanos, el gran maestro paulista les abrió el maravilloso camino que debían seguir.

* Lúcia Velloso da Silveira es una escritora e investigadora brasileña, que realizó estudios literarios bajo la conducción del notable maestro y crítico Alceu de Amoroso Lima. Ha recibido varias distinciones en Perú por su notable contribución a los vínculos entre la cultura del Perú y del Brasil, entre ellos el premio «Madre Teresa de Calcuta. Premio Nóbel de la Paz», que otorga la Asociación Civil Sembrando Valores. Ha sido directora del Centro de Estudios Brasileños en Lima. Ha publicado Português do Brasil para Hispano-americanos (1995), Mapa de Fondo. Português do Brasil para Hispano-americanos (1995), Verbos em Português (1995) y 20 rutas por el Brasil (1987, 2. a edición 2002), que reúne estudios sobre «Aleijadinho", Tiradentes, Câmara Cascudo, Alfredo D’escragnolle Taunay (Vizconde de Taunay), Monteiro Lobato, Carlos Gomes, Augusto Rodrigues, Manuel Bandeira, Jorge Amado y Carlos Drummond de Andrade; así como barroco brasileño, Independencia del Brasil, fiestas navideñas y juninas. 
Palabras Clave: literatura infantil, literatura brasileña, literatura latinoamericana, Monteiro Lobato, fantasía

AвSTRACT: In this paper we will present a historical path of Brazilian children's literature and highlight the importance of Monteiro Lobato, who opened the doors to a new kind of creativity in Latin American literature. His work is a great project that shows children not only the essential value of literature but also the extraordinary world of culture. Monteiro managed to combine two factors: reality in the reading of life along with fantasy, promoting creativity.

The great paulist master open the wonderful path for Brazilian as well as Latin-American writers that would come later.

KeYwords: children's literature, Brazilian literature, Latin American literature, Monteiro Lobato, fantasy.

\section{EL BRASIL DE AYER, ORÍGENES DE LA LITERATURA INFANTIL. EL PRECURSOR: FIGUEIREDO PIMENTEL}

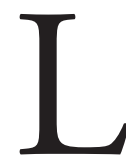

a Literatura Infantil en el Brasil comienza de modo oral y posee, en su esencia, tres raíces: la europea, la africana y la indígena. Cada una de ellas contribuyó con sus valores para la conformación de la cultura brasileńa y de ese contexto surgió, de manera espontánea, ese tipo de literatura.

Durante la época Colonial se destaca la figura de los akpalos (negros esclavos contadores de historias) que, conservando la tradición africana, iban contratados de hacienda en hacienda, cumpliendo su labor de «cuenta cuentos» para los niños blancos. Muchas de sus historias se mezclarían con las de las abuelas blancas y con las leyendas indígenas 
recolectadas principalmente por los catequistas, dando como resultado de ese proceso de interacción cultural una simbiosis cuya característica más relevante fue su temática riquísima, inagotable.

A fines del Brasil Imperio (1822-1889) y comienzos del Brasil República (1889), es decir, por la segunda mitad del siglo xIX y comienzos del xx se inician las grandes transformaciones de la sociedad brasileña, tales como la liberación de los esclavos (1888), el término de la Monarquía (1889) y el surgimiento de una relación de producción dada por el binomio capital/trabajo. Por entonces aparece también el libro en el Brasil y, con ello, la difusión de aquellos autores que conformarían la llamada «Biblioteca Clásica» de la Literatura Infantil y Juvenil. Nos referimos a Jonathan Swift (Viajes de Gulliver), Mark Twain (Las aventuras de Tom Sawyer), Jules Verne (Viaje al centro de la Tierra), Carlo Lorenzini Collodi (Las aventuras de Pinocho), Edmundo de Amicis (Corazón), entre tantos autores extranjeros leídos no solo en traducciones, sino en su expresión original.

Respecto a la producción brasileńa, aparece en su momento (fines del siglo xIx y comienzos del xx) una amplia literatura muy comprometida con la llamada «Escuela Nueva», ${ }^{1}$ sistema escolar entonces en boga que buscaba, dentro de un compromiso muy fuerte con la tríade literaturapedagogía-psicología, afirmarse en la necesidad de desarrollar una literatura propia, nacional y necesaria — según los especialistas - para la infancia brasileña.

Dentro de ese «ámbito escolar» surge un primer intento de realizar una Literatura Infantil mediante los llamados «Libros de Lectura». En ellos, sus autores demuestran estar conscientes de la necesidad de apartarse de los moldes culturales portugueses y de buscar lo propio, ofreciendo a los niños

1 A esta Escuela pertenecerían Pestalozzi, Decroly, Winnetka, Kerschensteiner, etc. 
realidades muy brasileńas, provenientes tanto del mundo natural que los rodea cuanto del relacionamiento familiar, teniendo en mente un mayor compromiso con los fenómenos socioculturales. Era ésta la reacción de una nación que se "civilizaba» a ritmo lento, siempre creciente, durante una época confusa de cambios acelerados en la que estaba emergiendo una clase media que buscaba su autoafirmación.

Esos «Libros de Lectura» sufrieron, en su mayoría, muchas restricciones, porque la preocupación didáctica sofocaba la creatividad, la libertad y la espontaneidad, vitalmente necesarias en las obras de literatura. Pero, de todos modos, representaban un esfuerzo pues fueron los primeros pasos para la creación del libro dedicado a la infancia y, al mismo tiempo, daban una idea de la enorme carencia que existía en esa área y del gigantesco esfuerzo que era necesario realizar a fin de superar tal situación. En este sentido, autores famosos de la literatura brasileña tomaron conciencia de la necesidad de crear libros para niños no parametrados, llegando así a publicarse una serie de obras infantiles de temáticas variadísimas. Podríamos mencionar, por ejemplo, a Alberto Figueiredo Pimentel (1869-1914), considerado el precursor de la Literatura Infantil en el Brasil, con Cuentos de la Carochinha, ${ }^{2}$ el primer libro para niños que él traduce; también adapta cuentos de otros países, además de recomponer la tradición oral que, hasta entonces, no había logrado la divulgación literaria. Este autor nacido en Río de Janeiro publica después otros libros donde aparecerán canciones de cuna, juegos y pasatiempos infantiles encontrados en la tradición popular.

$\overline{2}$ El libro comprende traducciones al lenguaje brasileño de 61 cuentos populares de diferentes autores (Perrault, Grimm, Andersen, etc.). 


\section{MONTEIRO LOBATO Y LA LITERATURA INFANTIL EN EL BRASIL DE HOY}

Otros autores seguirían a Alberto Figueiredo Pimentel, hasta que en 1921 surgió un escritor que iría a revolucionar la Literatura Infantil en Brasil y en Latinoamérica: José Bento Monteiro Lobato, nacido en 1882 en la ciudad de Taubaté, en São Paulo. Él encontró ese nuevo rumbo creador que hacía falta a la literatura infantil de su país, al publicar su libro Narizinho arrebitado (Naricita respingada), el primero de una serie de veintitrés títulos.

Monteiro Lobato fue el hijo mayor de una familia de hacendados, cuyas raíces se remontaban a los orígenes de la Colonia. Fue alfabetizado por su madre antes de ingresar a la escuela. Aún niño, descubrió el mundo de las letras en la gran biblioteca de su abuelo, el Barón de Tremembé. Luego de concluir sus estudios se graduó como abogado. A raíz de la muerte de su abuelo se hizo cargo de la hacienda. Años después vendió esa propiedad familiar y se fue a vivir a São Paulo. Ahí ejerció la profesión de escritor y de activo periodista en la vida brasileña, buscando el progreso social y mental de la gente. Seguramente fue con ese propósito que fundó la primera empresa editorial brasileña y publicó una serie de cuentos para adultos (Urupés 1918, Ciudades muertas 1919, Negrita 1920)³ , así como ensayos periodísticos sobre la idiosincrasia del habitante del interior del Brasil reunidos bajo el título de Ideas de Jeca Tatu (1919). Esta obra provocó grandes polémicas y un sinfín de sinsabores debido a que Lobato, racionalista y pragmático, retrataba allí al campesino brasileño en forma abiertamente realista, mostrando con eficacia y en tono patético las miserias físicas y mentales de aquellos seres marginales.

3 Otras obras para adultos fueron La ola verde (1921), El mundo de la luna (1923), El mono que se hizo hombre (1923), El choque de las razas o Un presidente negro (1926), Fierro (1931), El escándalo del petróleo (1936), etc. 
Dentro de ello vale señalar que este verdadero pionero del nacionalismo (en contra del espíritu oligárquico, tal como Euclides da Cunha y Lima Barreto) «encarnó al divulgador agresivo de la Ciencia, del progresismo, del «mundo moderno», siendo un demoledor de tabúes, a la manera de los socialistas fabianos, ${ }^{4}$ con un superávit de gracia y de sarcasmo» (Bosi 2006:216). En tal perspectiva dejó su imprenta para dedicarse a escribir sobre el desarrollo económico del país. Fue Agregado Comercial en Estados Unidos entre 1927 y 1931, y fundó la Compañía Nacional de Petróleo, producto natural y riqueza que defendió con inteligencia y coraje siendo por eso acosado, perseguido e incluso encarcelado. Murió en São Paulo, el 5 de julio de 1948.

\section{EL PREMODERNISMO DE MONTEIRO LOBATO Y SU OBRA}

\section{Naricita}

La conciencia nacionalista fue asumida por Monteiro Lobato dentro de un clima literario premodernista ${ }^{5}$, propio de la época. Ello se manifiesta al compartir sus intereses con la vida regional y con ciertas preocupaciones de carácter formal aún naturalistas y parnasianas, así como con la objetividad en la narración y en el vernaculismo del lenguaje.

Observando el interés de sus hijos en las fábulas contadas por su esposa, surgió en Monteiro Lobato la idea de que la Literatura Infantil que hacía falta al país podía comenzar por ahí, por un Fabulario, con animales conocidos de la fauna brasileña. Sin embargo, ese libro vendría después porque primero publicó, en 1921, un texto que llegó a ser el inicio de una etapa que separaría al Brasil de ayer del Brasil de hoy. Y Lobato

4 Persona simple, inofensiva.

5 Recuérdese que el Modernismo brasileño (Vanguardia para los hispanoamericanos) se inició en 1922, a través de la Semana de Arte Moderno. 
se constituyó, así, en la piedra angular de las venideras manifestaciones de la Literatura Infantil. Ese gran libro fue La niña de la naricita respingada, o Naricita, que causó un suceso espectacular entre sus pequeños lectores porque su autor cortó desde la base el racionalismo tradicional y abrió las puertas para un nuevo tipo de creatividad que necesitaba ser liberada. El factor decisivo para ello fue «la realidad común y familiar al niño en su vida cotidiana, súbitamente penetrada por lo maravilloso y por lo mágico, con la más absoluta verosimilitud o naturalidad. Monteiro Lobato mezcló lo real y lo maravilloso en una sola realidad» (Novaes 1981:356). Estos dos planos se fundieron y confundieron de tal modo que el hecho literario fue aceptado y vivido como algo natural, inherente a la vida diaria.

Este gran contador de historias dio entonces rienda suelta a su imaginación escribiendo para los niños como si él mismo lo fuera. De gran provecho fueron sus vivencias en el campo, sus antiguos juegos infantiles, su vasta cultura universal. Pero también lo fue el hecho de pertenecer a la estirpe de humanistas liberales imbuidos de nacionalismo consciente, de conocimientos de la psicología del hombre de su tiempo, del respeto por la sabiduría popular. En tal condición, como bien dice el poeta peruano Arturo Corcuera en el prólogo de su traducción de Naricita, "Monteiro Lobato contando cuentos enseña y libera, conmueve y entretiene» (Corcuera 1986:11); es decir, tuvo las cualidades y los dones del contador ideal que se expresa desde la experiencia personal.

Las obras infantiles e infanto-juvenil de este notable escritor abarcan, por los temas tratados, veintitrés títulos agrupados en textos «originales» $y$ «adaptaciones». Todos ellos están constituidos por narraciones de aventuras, en donde aparecen situaciones, personajes, celebridades, etc., que viven en la memoria de los tiempos, de la Historia, de la Literatura y de la Leyenda. En el grupo de los textos «originales» podríamos mencionar: Travesuras de Naricita, Memorias de Emilia, Fábulas, Emilia en el Pais de la 
Gramática, Historias de Tía Nastacia, Viaje al Cielo, etc. Sin duda, en ellos está el gran aporte de Monteiro Lobato, que es redescubrir realidades estáticas cristalizadas por la memoria cultural y darles nueva vida, mezclándolas con las travesuras de los niños que habitan el Sítio do Pica-pau amarelo ( La pequeña chacra del pájaro carpintero amarillo).

En el grupo de las adaptaciones están Don Quijote de los niños, El Minotauro, Historia del Mundo para los niños, Los doce trabajos de Hércules, etc. En este tipo de obras Monteiro Lobato tuvo un doble objetivo: por un lado, llevar a los infantes el conocimiento de la tradición (con sus héroes reales o ficticios, con sus mitos, con las conquistas de la Ciencia, etc.) y, por otro, el conocimiento del acervo heredado que les tocaría transformar e inclusive cuestionar, tomando en cuenta las verdades descubiertas y los valores y los no-valores que el tiempo ha cristalizado y que le corresponde al presente redescubrir o renovar.

Volviendo a las historias originales, éstas tienen como referente y punto de partida la citada pequeña chacra del interior de São Paulo: $O$ sitio do Pica-pau amarelo. En este lugar mágico viven personajes «reales» que son arquetipos, como por ejemplo Doña Benita (Dona Benta), dueña de la chacra, que es la abuelita ideal, aquella que acepta la imaginación creadora de los niños e inclusive los motiva en su curiosidad insaciable de conocimientos. Naricita y Pedrito — sus nietos — son los niños de siempre, alegres y sanos, sin problemas, listos a vivir todas las experiencias. Ellos dan el soporte a la trama de los acontecimientos y le hacen el contrapunto a la muñeca Emilia. La Tía Nastacia, por su lado, es el símbolo idealizado de la raza negra, afectuosa y humilde, presente en la génesis del pueblo brasileño y fuente importante de aquellas historias que alimentaron a muchas generaciones. Ella representa ese canal humano del folclore en la obra de Lobato. 
El Sitio do Pica-pau amarelo es, también, una especie de Reino do «Faz-de-conta» (Reino de lo imaginario), donde conviven aquellos seres reales ya mencionados; otros son extraídos de lo maravilloso, como por ejemplo la muñeca Emilia, el más famoso e importante personaje que merecerá una referencia especial más adelante. Estará también el Vizconde Barba de Choclo, mazorca representativa del sabio filósofo que cree en los buenos libros ya escritos; hay igualmente un chanchito apellidado Marqués de Rabicó que solo piensa en su estómago; y está el estoico burro Falante (burro parlanchín, hablador) y el Rinoceronte Quindim que es el bruto humanizado.

Todos ellos forman la base del universo lobatiano y están siempre presentes en las increíbles «travesuras» que se suceden en cada libro. El divertimento le da la unidad permanente a la obra. El hechizo o encanto dentro del mundo representado está conducido por personajes ocasionales gracias al "polvo de pirlimpimpím» que representa la fantasía, el mundo de la imaginación, lo mítico más allá del tiempo y del espacio. El «estar» se localiza en la chacra; los personajes y las aventuras más increíbles que aparecen en cada historia corresponden al «ser» (el tiempo). Todo esto es muy bien comprendido por los niños.

Habíamos dicho que a Emilia le ha de corresponder un espacio relevante. Efectivamente, ella está al frente de todos, como jefa y conductora. Es una muñeca de trapo que adquiere el don del habla gracias a unas píldoras parlanchinas del doctor Caracol. Es, también, la voz de su creador, su alter-ego, y tendrá, dentro de las características nietzschianas — filósofo admirado por Monteiro Lobato—, los rasgos del «superhombre»: llena de voluntad de dominio y exacerbado individualismo. Emilia aparecerá siempre con su espíritu de líder, con su prestigio de «mandona»y con la obstinación de quien mantiene su opinión hasta obtener sus propósitos. 
Monteiro Lobato sabe dosificar muy bien esas "actitudes emilianas»: si algunas veces las elogia en otros momentos las satiriza a fin de que ella se dé cuenta de que no siempre tiene la razón. Por ser muñeca y no gente, y por ser la única que tiene esas características, vive en permanente tensión con los demás. Pero atrae la simpatía inmediata del lector porque encarna las características «rebeldes» de los niños, que la aman y se identifican con ella, que vibran con su curiosidad abierta a todo, y con su gran franqueza para criticar los errores o las tonterías de los demás. También son simpáticas sus malacrianzas, su terquedad, su rebeldía, inclusive su viveza interesada, porque todo eso la acerca a lo humano sin hacerla perder su condición de ente mágico. Además, la naturalidad que la caracteriza se da mediante un lenguaje fluyente, coloquial, objetivo, sin retórica, donde el humor sano está siempre presente para proporcionar a la obra ráfagas de aire puro. Leamos un fragmento de Naricita en donde hay un interesante y perspicaz diálogo entre Emilia y Cenicienta:

Pedrito saludó a Cenicienta con una inclinación de cabeza. Y Emilia, olvidando todas las advertencias que se le hizo, se introdujo debajo de la silla de Cenicienta para observar de cerca sus célebres pies desnudos, calzados con los zapatitos más pequeños del mundo. Naricita estaba muy incómoda. Cenicienta, por el contrario, celebraba la ocurrencia de Emilia. Y tomándola en sus brazos, le susurró:

-Yo te conozco de nombre.

-Yo también conozco tu historia, le replicó Emilia. Pero hay un aspecto que no acabo de entender. Un libro dice que tus zapatos son de cristal, otro dice que son de raso y yo los acabo de ver que son de cuero. Cenicienta se echó a reír. En la fiesta donde conocí 
al Príncipe —comenzó a contar- estuve con zapatos de cristal. Pero eran sumamente incómodos, me sacaban callos. Por eso uso ahora zapatos de gamuza.

—¿De qué número?

-Treinta.

— ¿ Treinta? Mis pies son más pequeños. Calzo zapatos número tres y hasta hoy no he encontrado un Príncipe Azul.

-No pierdas la esperanza, Emilia - le dijo Cenicienta. Cualquier día puede hacer su aparición el Príncipe de tus sueños. (Monteiro 1986: 93-95)

Muchas cosas más podríamos decir de Monteiro Lobato, mago ilusionista de los sueños infantiles. Su obra es, no cabe duda, un gran proyecto que le muestra a la infancia no solo el valor esencial de la literatura sino, también, el mundo extraordinario de la cultura. Él supo conjugar los dos factores que le dieron tantos éxitos: la «realidad» en la lectura de la vida, junto con la «fantasía» que promueve la «creatividad». A los escritores que vendrían después, el gran maestro paulista les abrió el maravilloso camino que debían seguir.

\section{VISIÓN PANORÁMICA DE LA LITERATURA INFANTIL BRASILEÑA POST-LOBATO}

Según Nelly Novaes Coelho, una de las más profundas conocedoras de esta literatura: «En el Brasil, a pesar de la eclosión Modernista que insuflaba la fantasía y la imaginación, ellas serán reprimidas durante el período de reconstrucción de 1930, con la llamada «república nueva» del gobierno de Getulio Vargas. En efecto, el progreso económico ascendente habría de 
coincidir con las denuncias de injusticias sociales, económicas y políticas que oprimían principalmente a las regiones más alejadas del eje urbano RíoSão Paulo» (Novaes 1982:382).

La Literatura Infantil aparece en la década del 30-40 como un serio problema a ser tomado en cuenta: ella continuó siendo vista como un género menor. Al lado de los libros de Lobato y de las obras «clásicas» traducidas y/o adaptadas, «surge en ese período una producción infantil de inexpresivo nivel literario y de nítido carácter realista, directamente ligada a la enseñanza» (Novaes 1982:382).

\section{1. Manuel Viriato Correia}

Algunos escritores, sin embargo, escaparon a la mediocridad general. De entre ellos se destaca Manuel Viriato Correia (Maranhão, 1884-Río de Janeiro, 1967). Su libro más famoso, Cazuza, semejante al libro Corazón, de Edmundo de Amicis, de gran éxito entre los niños brasileños, es un «romance de aprendizaje», pero no a la moda europea, sino a la brasileña. En él está presente ese espíritu optimista, alegre, tropical, contrario al europeo (con sus rigores invernales y su seriedad retórica). El texto está escrito en un lenguaje coloquial y vivo, lo que le da un sabor de realidad auténtica. Cazuza es un documento interesante para mostrarnos cómo eran las relaciones familiares y sociales en el Brasil de la época; cómo eran la escuela, las diversiones, los ideales, los prejuicios y las supersticiones, las peculiaridades regionales, entre otras manifestaciones culturales. En general se vivía un momento en que la enseñanza a los niños y a los jóvenes —a través de libros sobre modos de vivir, pensar y comportarse en sociedad - superaba la preocupación por divertirlos. 
Cabe destacar, también, que además de la producción literaria en libros empieza a ganar importancia el fenómeno de las revistas, de las «historias en diseños», que además de su intención didáctica o educativa sufría la manipulación de los medios de comunicación masivos con la finalidad de distraer (por la radio, el cine y la televisión a partir de los años cincuenta, y por el merchandising hasta ahora).

Concurriendo con la tendencia general del realismo cotidiano aparecen, «importadas», las llamadas «grandes aventuras», conteniendo tres tendencias básicas:

1. La atracción por la naturaleza; ejemplo: Tarzán (en diseños); Jim de la Selva, Popeye; también animales transformados en héroes: Gato Félix, Mickey Mouse, Pato Donald, etc.

2. ${ }^{\circ}$ Lo fantástico: los héroes invencibles, los mundos y seres extraños: Flash Gordon, Mandrake, Superman, Batman (en diseños).

3..$^{\circ}$ El realismo violento - género policial para adultos-a través de Estados Unidos, también leído por los jóvenes.

\section{2. Lúcia Machado de Almeida y otros escritores}

De 1940 a 1950, atendiendo los requisitos didácticos de la literatura infantil de ese momento y simultáneamente realizando una labor literaria considerada de un buen nivel, la escritora Lúcia Machado de Almeida armoniza en su obra, publicada entre 1943 y 1945, los principios de la Literatura Infantil y Juvenil cimentados por el maestro Monteiro Lobato: «realidad, fantasía y conocimiento». Ella escribió En el fondo del mar, El 
misterio del pueblo, La región de los peces fosforescentes; todos ellos fueron reunidos en un solo volumen titulado Historias do fundo do mar (Historias del fondo del mar).

Después del final de la guerra, en 1945, se promueve en el Brasil los métodos de la llamada «Escuela Nueva» pero de un modo exagerado porque no se incentiva básicamente el quehacer propiamente literario, sino la intención didáctica. Esto resulta más lamentable porque los libros de Monteiro Lobato son acusados de perniciosos para la infancia debido a la atmósfera de libertad que respiran y a ese énfasis en la fantasía, el sueño y la imaginación creadores. Por todo ello comienzan a ser prohibidos en los colegios religiosos.

Aparece entonces abundante producción de libros que no hablan de «irrealidades» o de lo «maravilloso», que no contienen nada que sirva de «alienación» a la infancia. Lo cierto es que casi todos son mediocres y sin ningún valor literario; y esto se debe muchas veces no al tema elegido sino a la falta de talento de sus autores que solo escriben para enseñar algo, y nada más. En otros casos, pensando en sensibilizar a sus pequeños lectores, infantilizan el lenguaje; lo endulzan, por ejemplo, con un alarmante abuso de diminutivos.

Pero las obras de los cuentos maravillosos antiguos y los «clásicos» son reeditados y se mantienen preferidos por los niños. Felizmente aparecen también buenos escritores. Entre ellos tenemos a Francisco Marins, que escribe a partir de 1945, para lectores infanto-juveniles, una serie titulada «Taquara-Poca», abordando un tema que llama la atención: la vida rural del Brasil prácticamente desconocida por los habitantes urbanos. Otros buenos escritores también destacaron en esa época, como María José Dupré, María Lúcia Amaral, Odette de Barros Mott, etc. 


\section{3. La figura actual de Ana María Machado}

Los parámetros actuales de la Literatura Infantil cubren tres tendencias: la «Realista», que expresa lo «real» y busca algunos de los siguientes objetivos: mostrar el mundo cotidiano, actual; informar sobre costumbres, hábitos o tradiciones populares de diferentes regiones brasileñas; incitar la curiosidad del lector para los hechos insólitos que suceden en la vida diaria; preparar a los lectores para que enfrenten los dolores y los sufrimientos de la vida. La segunda tendencia es la «Fantástica», en donde la ficción predomina sobre lo real. Finalmente está la «Híbrida», que es el dominio del Realismo Mágico en el cual lo Real y lo Maravilloso se funden y se confunden. Hay una gran cantidad de escritores que transitan por ese camino. Por ahora deseamos referirnos brevemente a una creadora que es un clásico de la Literatura Infantil brasileña: Ana María Machado.

Ana María Machado nació en Río de Janeiro en 1941. Es un ícono de la Literatura Infantil, con más de cien títulos publicados. Ha ganado innumerables premios como el más importante a nivel mundial: el Hans Cristian Andersen, en el año 2000. Su labor creativa se basa en una actitud exigente y rigurosa que evita la «infantilización» de esa literatura a favor del acto creador del lenguaje. Esta brillante autora conoce como pocos el poder mágico que posee ese género literario. Para ella las palabras se presentan con tanto poder que es inevitable atraer la curiosidad del niño, despertando sus reflexiones sobre ellas, sus especulaciones intelectuales; ella confesará sobre su impronta creadora: «Probablemente, en la raíz del descubrimiento de una voluntad (vocación) de escribir, está esa fascinación, ese gusto por tratar a las palabras como juguetes inagotables. Por lo menos, puedo garantizar que a mí me ocurrió eso. Los críticos señalan que ésa es una de las características más notables de mis libros, y reconozco que tienen toda la razón» (Machado 2002). 
Ana María, pues, descubre y utiliza la magia de las palabras; ella conoce muy bien el poder que tienen en los cuentos populares y en todo el folclore infantil en tanto manifestación de cultura oral que pasa de generación en generación y en donde se busca comprender o se intenta controlar el mundo por medio precisamente de las palabras. Este mundo mágico que está en ellas y en donde el juego es fundamental, aparece en todo su esplendor en el cuento Palabras, palabritas y palabrotas.

La prosa de Ana María Machado se nutre principalmente de lo coloquial y de la oralidad, utilizando los giros propios del habla cotidiana; de este modo llega rápida y efectivamente al pequeńo lector y a la vida que lo caracteriza en el mundo actual:

Para comenzar, un terreno tenía que ser de tierra, claro. Y el tal playground era de cemento. No tenía tierra, ni arena, ni lombrices, ni cucarrones, ni grillos, ni hierbas, ni arroyos, ni ranas, ni piedras, ni caracoles, ni pasto, ni musgo, ni mariposas, ni mariquitas, ni tantas cosas que si se hiciera la lista completa, no terminaríamos. Realmente era enorme.

Enorme también, casi infinito, era el tamaño vacío que Diego sentía dentro de sí a veces, cuando tenía ganas de soñar con prados y campiñas como las que veía en la televisión. Pero se tenía que contentar con aquel cemento de color ceniza. (Machado 2000:10-11)

Otro recurso admirable de la cuentística machadiana es la retahíla acumulativa de palabras paranomásicas, como aparece, desde el título de sus 


\section{LA LITERATURA INFANTIL EN LATINOAMÉRICA}

obras, en Camilón Comilón, Curruspaco papaco, Bisa Bía, Bisa Bel. ${ }^{6}$

Y habría que enfatizar que la renombrada escritora, tal como sucede con otros importantes escritores de Literatura Infantil, sabe destacar:

El valor de la ficción que no es igual a evasión. La expresión (la formación lingüística) no agota el lenguaje literario puesto que el texto es más que eso, es también «representación» o creación de un mundo (representación o evocación surgida del propio texto, de su "significado intensificado») el cual, a nivel de connotación, puede ser simple o complejo. (Pantigoso2005:79).

Ana María Machado es, también, una ardua defensora de la divulgación de la Literatura Infantil en todos los niveles sociales a fin de que las personas tengan la posibilidad de compartir una herencia humana universal y puedan crecer como seres humanos. Para ella, los colegios y las universidades tienen la función de formar e informar, mostrando cómo se lee correctamente, de manera crítica para permitir el desarrollo del pensamiento. Y esto no se puede lograr si se dan a los alumnos libros frívolos y superficiales solo porque están de moda. Los alumnos tienen derecho de estar en contacto con lo mejor que la humanidad ha venido produciendo.

Esta y laureada escritora, una de las más lúcidas de nuestro tiempo, traducida a muchos idiomas, está comprometida con el mundo que le ha tocado vivir. Ella se refiere a la resistencia de la Literatura Infantil como fenómeno cultural capaz de mostrar nuestras identidades. Para todos los que estamos conscientes del valor innegable de esta literatura, esa resistencia

6 Otras obras de Machado son La abuelita aventurera, Ah pajarita, si yo pudiera, Del tamaño justo, Un deseo loco, Misterios del océano, Ojos, penas y plumas, Raúl pintado de azul, El domador de monstruos, Pimienta en la cabecita, El barbudo y el coronel, Un buen coro, Un montón de unicornio, Todo al mismo tiempo ahora, Del otro mundo, etc. 
significa «no aceptar que se convierta en otro bien de consumo, o por lo menos, que el mercado y el consumo no sean su punto de partida y su justificación. Pero sobre todo, resistir es defender estéticamente nuestras diferencias culturales, lo que nos hace ser quienes somos» (Arenes 2000: 3).

Otra veta importante de la literatura infantil es — sin duda - la que se refiere a la poesía, sobre la cual nos referiremos en otra oportunidad. Por ahora mencionaremos solo algunos escritores: Vânia Amarante, Odylo Costa Filho, José Elías, Antonieta Dias de Moraes, Sidônio Muralha, Roseana Murray, Marcos Accioly, Henriqueta Lisboa. Esta última posee sensibilidad y delicadeza naturales, pero con una visión más propia del adulto como sucedía por los años 1940. Su intencionalidad lúdica va acompañada de la acostumbrada «lección» propia de la escuela. Esta actitud aparece en Antología Poética para la Infancia y la Juventud y en Literatura Oral para la Infancia y la Juventud, que son de los años 60.

\section{EL TEATRO INFANTIL: MARÍA CLARA MACHADO}

Por los años 50 y 60 aparece un interesante movimiento de formación del Teatro Infantil. Dos autoras se destacan en esta tarea: Stella Leonardos, nacida en Río de Janeiro, en 1923, quien además de ser autora de cuentos infantiles reúne sus piezas teatrales en volúmenes: Teatro para niños (1962, 1967) y Seis piezas para niños (1970). Lo que predomina en esas obras es la unión de lo poético con lo folclórico; el tiempo, tanto el presente como el pasado juegan un papel importante en este Teatro de tipo experimental.

Pero la figura decisiva en la creación y el desarrollo del Teatro Infantil en el Brasil es María Clara Machado, que impulsó la conciencia de «hacer teatro» al fundar el grupo «Tablado» y la Escuela de Teatro de Río de Janeiro, semillero éste de destacados actores brasileños. Nacida en Minas 
Gerais, en 1921, pero radicada en Río de Janeiro donde falleció en el 2001, ella creó, desde 1950, una obra fecunda ligada con el folclore brasileño y también con los temas infantiles consagrados por la tradición. Sus piezas fueron traducidas a varios idiomas y también escenificadas en casi todo el Brasil. Algunas de las más conocidas son Pluft, el Fantasmita, El caballito azul, El rapto de las cebollitas y La niña y el viento. Su trascendente labor como directora, actriz de teatro y cine, dramaturga y traductora la colocaron en un sitial preponderante.

Los finales de esa década del cincuenta y comienzos de los sesenta, marcan el inicio de una nueva era: la de los audio-visuales (televisión, radio, proyectores de slides, etc.). La imagen reemplaza con ventaja a la palabra escrita. Hay, como consecuencia, una desarticulación entre lo viejo y lo nuevo. En ese momento lo importante es ser «un hombre bien informado». Esto se acentuará más adelante con la difusión de las computadoras. El realismo sobrepasa las naturales dimensiones humanas. El hombre empieza a dominar el espacio planetario. De ahí que lo real sobrepasa a la fantasía, y lo maravilloso entra de modo triunfal en la literatura.

\section{LA FUNDACIÓN NACIONAL DEL LIBRO INFANTIL Y LA «RONDA DE LOS LIBROS»}

En la mitad de la década de los sesenta surge una inquietud muy grande ocasionada por la falta de preparación de los alumnos. Esto se debe, según los investigadores, a la desvalorización de lo literario y de lo lingüístico en favor de lo visual y del fragmentarismo - dominantes en todos los sectores de la sociedad lo que da a los individuos una nueva conciencia del mundo-. Este alud de informaciones visuales, tan dispares, producto de la «comunicación de consumo", provocó un gran impacto en el ser humano hasta dominarlo, dejándolo sin tiempo para conectarse consigo mismo a fin de concentrarse 
y reflexionar. Esto — dijeron bien los estudiosos- habría de provocar una inercia mental en las grandes masas dominadas por un mundo interior apático, sin las fuerzas vitales capaces de estructurar los ideales, mientras externamente vivían una vida cada vez más acelerada.

Frente a esa realidad, los responsables de la educación y la enseñanza buscaron nuevas formas para incentivar la lectura y la comprensión de los textos literarios. Surgirá entonces la reorganización de las Bibliotecas Infantiles a fin de orientar mejor la lectura de los niños. Con el mismo propósito se creó, en 1968, la Fundación Nacional del Libro Infantil y Juvenil. Las Editoras de Literatura Infantil desarrollaron las «fichas de lectura» con la finalidad de orientar a sus lectores en la comprensión de lo leído. Surgió también la llamada «Ciranda de Livros» (Ronda de libros), una especie de biblioteca básica anual compuesta de quince a veinte títulos técnicamente seleccionados y distribuidos en más de 30,000 colecciones para las escuelas necesitadas. Esta experiencia alcanzó enorme éxito y fue una propuesta brasileña para toda la hermandad latinoamericana.

A partir de entonces el número de escritores interesados en escribir para niños y jóvenes creció poco a poco. Se vivió algo así como el redescubrimiento de la cultura y de la literatura, y también del niño. Luego, por los setenta, las tendencias de la Literatura Infantil se fueron definiendo y afirmando. Los escritores, liberados de lo puramente «didáctico», buscaron nuevos estilos y temas capaces de combatir la inercia mental y esa incapacidad para ver y apreciar lo nuevo. Procuraron, para ello, incentivar la voluntad, liberar el mundo interior, luchar contra la pobreza del lenguaje para expresar sus pensamientos, etc.

Los últimos autores continúan estimulando la conciencia crítica de sus lectores apuntando no solo a los valores ya desfasados sino proponiendo nuevos valores. Son escritores conscientes de que entre la realidad y la fantasía 
hay una relatividad en cuanto a límites y reglas absolutas, mostrados por la visión antigua y convencional. Es necesario — dicen — desterrarlos para que una nueva visión se instaure. No habrá, entonces, un único ideal literario para la Literatura Infantil pero sí un ideal que corresponda a la época y al lector al cual se destina. Algunos de los escritores más significativos de la hora actual son, sin duda: Ana María Machado, Carlos de Marigny, Edy Lima, Fernanda Lopes de Almeida, João Carlos Marinho, Lúcia Pimentel de Sampaio Góes, Lygia Bojunga, Marina Colasanti, Ruth Rocha, Stella Carr, Teresa Noronha, Ziraldo, etc.

\section{ADENDA I}

Al tomar conciencia de la importancia de la literatura para niños, muchos poetas famosos, con obras para adultos, pusieron todo su talento a favor del texto poético para los infantes y los jóvenes. Se convirtieron, así, en verdaderos modelos de lo que debe ser la literatura infantil sin «infantilismos». Dentro de una buena cantidad de grandes poetas, queremos destacar a tres de ellos: Cecilia Meireles, Mario Quintana y Vinicius de Moraes.

El caso de Cecilia Meireles (1901-1964) es emblemático. Con gran dominio del lenguaje, en el libro $O$ esto o aquello demuestra, a través del juego de la sonoridad y del ritmo de las palabras, las relaciones que deben existir entre el hombre, la naturaleza y la poesía:

Esta niña

tan pequeñita

quiere ser bailarina. 
No conoce ni el do ni el re

pero sabe quedarse en punta de pie.

No conoce ni el mi ni el fa

pero el cuerpo inclina de acá para allá.

No conoce ni el la ni el si

pero cierra sus ojos y ríe con frenesí.

Gira, gira, gira con los bracitos al viento

y no se marea ni sale de su contento.

Se pone en el cabello una estrella y un velo

y dice que ellos cayeron del cielo.

Esta niña

tan pequeñita

quiere ser bailarina.

Pero después olvida todas sus danzas

y como los otros niños quiere también dormir

y descansar de sus andanzas.

(«La bailarina»)

Otro poeta de gran inspiración es Mario Quintana (1906-1994), en cuya obra para niños predomina el ludismo, el humor, la sorpresa:

«Pajarito desventurado...

¡Qué bichito más asustado! 
Un mosquito basta, un zumbido

¡Y él despierta afligido!

Ahora mismo despertó.

¿Será que oyó o que soñó?

Furtiva sombra viene, suave,

Y ni aspira de miedo el ave».

(«Pie de pato»)

Finalmente, nombramos a Vinicius de Moraes (1913-1980). Este gran vate conocido por haber participado con inspirados textos en el movimiento de música popular llamado Bossa Nova, tiene un notable repertorio de poesía para niños en donde sobresalen las posibilidades del lenguaje sonoro y sus innúmeras travesías lúdicas. Muchas de sus poesías fueron musicalizadas y grabadas:

De un lindo salto

Ágil y seguro

El gato pasa

Del suelo al muro

Luego

Mudando de opinión

De nuevo pasa

Del muro al suelo

$\mathrm{Y}$ entonces corre

Furtivo y leve

Detrás de un 
Pajarillo

Pobre

Luego se para

Como asombrado

Y se dispara

Y salta de lado

Y cuando todo

Ya le fatiga

Su baño toma

Pasando la lengua

Por la barriga.

(«El gato»)

\section{ADENDA II}

Las obras de Monteiro Lobato traducidas al español se difundieron con mucha aceptación por toda la América Hispana. Cuando por los años ๙ิ cuarenta la escritora peruana Carlota Carvallo de Núñez comienza a escribir sus cuentos para niños, los libros del brasileńo estaban en pleno auge en el Perú. Los puntos de contacto que podemos encontrar relacionados con la concepción de cómo debe ser una obra infantil la acercan a Lobato y nos permite aseverar que la gran escritora, música y pintora peruana conocía, complacida, los principios ejercitados por el gran maestro brasileño, sintetizados en ese equilibrio que debe haber entre realidad y fantasía. Sobre Carvallo de Núñez, Manuel Pantigoso dice «sus personajes y sus historias tienen un marcado hálito fantástico pero la atmósfera imaginativa siempre los vinculará a su medio, a su entorno respectivo, para que sean físicamente reales y auténticos en sus conductas» (2010: 494). 
Los cuentos de la excelente escritora peruana tienen como fuente principal la oralidad y algunos de los más celebrados aparecieron, póstumamente, en 1990, bajo el título de La niña del espejo y otros cuentos. Por sus méritos ella es considerada «la fundadora de la moderna Literatura Infantil Peruana» (Pantigoso 2010: 494). Con su obra dejó claro que este género literario podía y debía tener todas las fantasías posibles para afirmarse más en la realidad, pero sin ningún tipo de manipulación.

Al lado de Carlota Carvallo de Núñez vendría, poco después, Francisco Izquierdo Ríos, con sus Cuentos del Tío Doroteo (1950). Los dos se tornarían en un ejemplo y un símbolo de todo ese fenómeno creativo que tiene, claro está, un referente «infantil», pero sobre todo es Literatura. 


\section{BIBLIOGRAFÍA}

Arenes, Carolina

2000 Diario La Nación. Buenos Aires.

Bosi, Alfredo

1987 História concisa da Literatura Brasileira. 3. ${ }^{a}$ ed. São Paulo Ed: Cultrix.

LOBATO MONTEIRO, José

1986 Naricita. Traducción y Prólogo de Arturo Corcuera. Lima: Embajada del Brasil.

Cabel, Jesús

2005 Alero de los sueños: seis rutas para la literatura infantil. Lima: Editorial Hozlo.

Machado, Ana María

2000 Un montón de Unicornios. Colombia: Editorial Norma.

2002 I Congreso Latinoamericano de Literatura Infantil y Juvenil. Montevideo. (HTTP: //www.imaginaria.com.ar)

Novaes coelho, Nelly

1982 A Literatura Infantil. 2a ed. São Paulo: Ed. Quíron/ Global.

1992 Dicionário Crítico da Literatura Infantil/ Juvenil Brasileño. São Paulo: Ed. Global. 
Pantigoso, Manuel

2010 Estuardo Núñez y la Generación de la Crisis. Lima: Editorial Hozlo.

Pimentel Góes, Lúcia

1984 Introduçao à Literatura Infantil e Juvenil. São Paulo: Livraria Pioneira Editora.

Vasconcelos de Carvalho, Bárbara

1989 A Literatura Infantil. 6. ${ }^{a}$ ed. São Paulo: Ed. Global.

Velloso da Silveira, Lúcia

201022 rutas por el Brasil. Lima: Editorial Hozlo. 